\title{
Psicologia, psicanálise e educação: contrastes culturais e acadêmicos entre Brasil e Angola
}

\author{
Maria de Fátima Cardoso Gomes ${ }^{1}$; https://orcid.org/0000-0002-6881-3193 \\ Maria Inês Mafra Goulart'; https://orcid.org/0000-0002-8317-7746 \\ Marcelo Ricardo Pereira'; https://orcid.org/0000-0002-0977-9124
}

\begin{abstract}
Resumo
Este artigo apresenta uma pesquisa realizada pela Faculdade de Educação da Universidade Federal de Minas Gerais (UFMG), Brasil e o Instituto Superior de Ciências da Educação da Universidade 11 de Novembro (UON), Angola. Procurou-se responder a questões: "quem pesquisa o quê" e "para quê", no campo da psicologia educacional. A metodologia proporcionou imersão nas duas realidades por meio de missões de estudo e trabalho onde professores e estudantes da UFMG estiveram na UON em Angola e professores e estudantes daquela universidade estiveram na UFMG, Brasil. Valeu-se de princípios etnográficos em Grupos Operativos. Os resultados nos levaram a: compreender a realidade social de Cabinda em contraste com a realidade brasileira; construir uma nova identidade para o profissional de psicologia do ISCED-UON; implantar o Laboratório de Psicologia, Psicanálise e Educação (LPPE) e a Linha de Pesquisa, como uma possível resposta às demandas de produção de conhecimento da realidade de Cabinda/Angola.
\end{abstract}

Palavras-chave: Psicologia; psicanálise; educação.

\section{Psychology, psychoanalysis and education: cultural and academic contrasts between Brazil and Angola}

\begin{abstract}
This article presents a research carried out by the Faculty of Education of the Federal University of Minas Gerais (UFMG), Brazil and the Higher Institute of Education Sciences of the University 11 de Novembro (UON), Angola. We tried to answer questions: "who searches for what" and "for what", in the field of educational psychology. The methodology provided immersion in both realities through study and work assignments where UFMG professors and students were at UON in Angola and professors and students from that university were at UFMG, Brazil. He relied on ethnographic principles in Operational Groups. The results led us to: understand the social reality of Cabinda in contrast to the Brazilian reality; to construct a new identity for the ISCED-UON psychology professional; to implant the Laboratory of Psychology, Psychoanalysis and Education (LPPE) and the Research Line, as a possible answer to the demands of production of knowledge of the reality of Cabinda / Angola.
\end{abstract}

Keywords: Psychology; psychoanalysis; education.

\section{Psicología, psicoanálisis y educación: contrastes culturales y académicos entre Brasil y Angola}

\begin{abstract}
Resumen
En este artículo se presenta una investigación realizada por la Facultad de Educación de la Universidad Federal de Minas Gerais (UFMG), Brasil y el Instituto Superior de Ciencias de la Educación de la Universidad 11 de Noviembre (UON), Angola. Se buscó contestar a cuestiones: "quién investiga que" y "para qué", en el campo de la psicología educacional. La metodología proporcionó inmersión en las dos realidades por intermedio de misiones de estudio y trabajo en que profesores y estudiantes de la UFMG estuvieron en la UON en Angola y profesores y estudiantes de aquella universidad estuvieron en la UFMG, Brasil. Se usó de principios etnográficos en Grupos Operativos. Los resultados nos llevaron a: comprender la realidad social de Cabinda en contraste con la realidad brasileña; construir una nueva identidad para el profesional de psicología del ISCED-UON; implantar el Laboratorio de Psicología, Psicoanálisis y Educación (LPPE) yla Línea de Investigación, como una posible respuesta a las demandas de producción de conocimiento de la realidad de Cabinda/Angola.
\end{abstract}

Palabras clave: Psicología; psicoanálisis; educación.

1 Universidade Federal de Minas Gerais - Belo Horizonte - MG - Brasil; mafacg@gmail.com; marinesmg@gmail.com; mrp@fae.ufmg.br 


\section{Introdução}

O propósito deste texto é apresentar os primeiros resultados de uma pesquisa realizada pela Faculdade de Educação da Universidade Federal de Minas Gerais (FaE-UFMG)/Brasil e o Instituto de Ciências da Educação da Universidade 11 de Novembro (ISCED-UON)/Angola, numa parceria firmada por meio do Programa de Pró-Mobilidade Docente e Discente Internacional/CAPES/AULP. Este Programa Internacional de apoio à Pesquisa e ao Ensino tem por objetivo a estruturação, o fortalecimento e a internacionalização dos Programas de Graduação, Pesquisa e Pós-Graduação das universidades integrantes da Associação das Universidades de Língua Portuguesa (AULP), da qual fazem parte as universidades protagonistas deste projeto.

Esse trabalho transcorreu entre os anos de 2013 e 2015 no Brasil e em Angola. Neste artigo, procuramos responder questões como: o que se pesquisa no campo da Psicologia Educacional dos dois países, na tentativa de situar suas realidades sociais, suas demandas de estudos em nível de graduação e pós-graduação que possam gerar reflexões para contribuir para a transformação da realidade e para subsidiar políticas públicas de qualidade no que se refere a esse campo. O estudo desenvolvido por meio do convênio firmado teve como objetivo a criação e implantação junto ao ISCED-UON do Laboratório de Ensino e Pesquisa e da Linha de Pesquisa Psicologia, Psicanálise e Educação, à maneira do que já ocorre na FaE-UFMG.

A pesquisa contou com uma equipe composta por: do lado angolano, um coordenador e três docentes do ISCED-UON e três alunos de graduação do curso de Licenciatura em Psicologia; do lado brasileiro, uma coordenadora e outros dois professores da FaE-UFMG, quatro alunos da graduação em Psicologia e Arquivologia e dois alunos de doutorado em Educação. A metodologia utilizada previu a construção do material empírico que demandou a estadia de professores e alunos em ambos os países (brasileiros em Angola e angolanos no Brasil), uma imersão nas duas realidades, característica dos estudos etnográficos. Para a análise do material empírico nos valemos dos princípios da pesquisa etnográfica contrastiva e interpretativa das diferentes realidades e culturas. Convivemos com professores, estudantes, diretores e reitores das duas universidades através de missões de trabalho e de estudo por mais de dois anos, o que nos possibilitou contrastar e interpretar as duas realidades.

Para desenvolver o trabalho, valemo-nos de nossa experiência brasileira como professores pesquisadores no Laboratório de Psicologia, Psicanálise e Educação - LAPED, pertencente à Faculdade de Educação da UFMG, que desde 1968 vem formando pedagogos e professores de Educação Básica de diversas áreas. Ao longo desses anos houve a criação da Pós-Graduação que hoje abriga diferentes linhas, laboratórios e grupos de pesquisa na FaE-UFMG - entre estes o laboratório em referência1.

\footnotetext{
1 Na época de sua fundação em 1998, sob o nome Laboratório de Psicologia da Educação Helena Antipoff.
}

As bases históricas que ajudam a instituir o LAPED encontram-se no bem-sucedido Centro de Documentação e Pesquisa Helena Antipoff(CDPHA), fundado no início de $1980^{22}$, que tem preservado a memória e divulgado a obra da educadora Helena Antipoff (1892-1974); psicóloga de origem russa radicada no Brasil a partir de 1929, responsável por instituir um dos primeiros laboratórios de psicologia estabelecidos no país (Laboratório de Psicologia da Escola de Aperfeiçoamento de Professores de Belo Horizonte) e pela fundação da cátedra de Psicologia na UFMG, em 1940.

De parte do ISCED/UON, fincado no enclave de Cabinda, na República de Angola, a prática de seus professores reflete os estragos e sofrimentos vividos nos anos de conflitos armados desde sua libertação dos portugueses em 1975 até o fim da guerra civil em 2002. Depois disso, o país vem enfrentando diversos desafios, em especial, o de tornar-se uma nação, sendo formado por expressiva diversidade étnica e política, muitas vezes, antagônicas entre si. Descrever a realidade político-social de Angola é bastante complexo, uma vez que os povos que constituem a nação angolana apresentam não só diferenças etnolinguísticas, mas também níveis díspares de integração social, política, educacional e econômica. No dizer de Bembe, "nos anos [19]70 Cabinda é emancipada e corajosamente incorporada na então futura República de Angola" (Bembe, 2013, p. 38). A UON (Universidade 11 de Novembro), de Cabinda, foi criada em maio de 2009, por meio do Decreto $n^{\circ}$. 7/09 (2009) que estabeleceu uma reorganização da rede de instituições de ensino superior pública daquele país, na tentativa de sua reconstrução no período de paz. Sua estrutura compõe-se dos seguintes cursos: Ensino de Psicologia, Ensino de Pedagogia, Ensino de Matemática, Ensino de Biologia, Ensino de História e Ensino de Língua Portuguesa.

Dentre esses cursos, os de Ensino de Psicologia, Ensino de Pedagogia e o recente Programa de Pós-Graduação do ISCED foram objeto de nossos estudos. APós-Graduação é nascente e se reduz à criação do curso de Mestrado em Educação com três linhas de pesquisa: Psicologia Escolar, Educação Matemática e Metodologia do Ensino Superior.

O curso de Licenciatura em Psicologia apresentou problemas graves em sua estrutura e destino dos profissionais no mercado de trabalho, uma vez que não há demanda de um grande número de professores de Psicologia na cidade de Cabinda e na província de mesmo nome. Porém, parece haver grande demanda de outro perfil profissional, formado em Psicologia, que pudesse desenvolver trabalho conjunto com os professores da escola básica nos muitos problemas por ela enfrentados.

Que profissional seria este? Essa questão problema foi anunciada pelo coordenador da pesquisa pelo ISCED, logo no início do estudo e se tornou o carro chefe da investigação. Logo de início, ficou claro que havia necessidade de nos debruçarmos no entendimento do perfil de um profissional, da área da Psicologia (e não do licenciado em Psicologia) que pudesse atender à demanda social de compreen-

2 Fonte: https://cdpha.wordpress.com/ - acessado em 30 jun. 2015 
são dos problemas dos alunos da educação básica relativos ao desenvolvimento e às dificuldades de aprendizagem, ao fracasso e evasão escolares, bem como à infância, à adolescência, ao alcoolismo precoce de jovens da província. Tratava-se, portanto, de estruturar um perfil de profissional, sugerido pelos professores brasileiros como Psicólogo Escolar e Educacional, que em parceria com os Pedagogos pudesse trabalhar no Sistema Educacional (nas escolas e fora delas) procurando soluções para os problemas emergentes do ponto de vista socioeducacional na comunidade cabindense. Para isto, segundo os professores angolanos haveria que:

introduzir a variante "PSICOLOGIA ESCOLAR" no lugar de "ENSINO DE PSICOLOGIA" para garantir a formação de profissionais competentes que garantissem o correcto funcionamento do ensino em Angola, ( conforme Decreto $n^{\circ} 95 / 80$ ). Ou seja, haveria necessidade de mudança curricular profunda para formar profissionais capazes de atender aos interesses supremos da nação nas questões relevantes da educação, do ensino-aprendizagem, questões relativas às dificuldades de aprendizagem de crianças e adolescentes, questões de adaptação escolar, de conflitos pais - filhos, escola - comunidade, professor - aluno, aluno -aluno, formação - emprego ou mercado de trabalho, estágio profissional de finalistas e de pesquisa continuada sobre questões de educação,ensino, aprendizagem durante toda vida e escolarização de crianças, jovens adolescentes e até, adultos etc. (ISCED , 2014).

O curso de Ensino de Pedagogia tinha, à época da pesquisa, uma matriz curricular bastante semelhante ao do curso de Licenciatura em Psicologia. Afora as disciplinas mais gerais, encontramos dez disciplinas comuns entre os dois cursos, diferenciando-se apenas no que concerne às disciplinas de Metodologias. Assim, o curso de Licenciatura em Pedagogia possui dez disciplinas de diversas metodologias, além de literatura infantil, ortografia e redação que não constam no currículo do curso de Licenciatura em Psicologia. Este último, por sua vez, distingue-se do anterior por conter sete disciplinas específicas no campo da Psicologia.

O que tentamos mostrar aqui, para dar início à discussão é um amalgamento entre os dois cursos de Licenciatura dificultando a construção de uma identidade dos dois profissionais, o que vem ocasionando desagrado e descrença no profissional licenciado em Psicologia. Além disso, por falta de mercado de trabalho, esse profissional tem se formado da área de Psicologia, mas atuado como professor das mais diversas disciplinas como matemática, educação física e outras, como se observa na fala dos alunos, na discussão do material empírico a seguir.

Agora cumpre também demonstrar que na finalização dos cursos de Licenciatura em Psicologia e em Pedagogia e de todos os outros há uma preocupação da direção da universidade em exigir uma produção acadêmica dos alunos nos moldes da monografia. Segundo Canhici (2014, p. 35), que analisou, em dissertação de mestrado, 41 monografias dos cursos em referência, muitos alunos também incorporaram a importância da monografia em seus processos de formação acadêmica:

A monografia é, no nosso ponto de vista, um elemento essencial e imprescindível na vida acadêmica do estudante. Seus efeitos práticos conduzem a uma nova visão que se tem sobre um determinado assunto. Mais do que isso, é um grande contributo à produção científica que se quer cada vez mais. A elaboração da monografia é um exercício considerado por muitos como desnecessário na prática educativa, mas achamos estarem completamente enganadas as pessoas que assim pensam. Apesar de reproduzir em nós um dispendioso consumo de energia, ser um pesado fardo e até certo ponto proporcionar um grande desgaste emocional, pouco se pensa, se discute ou se escreve sobre os benefícios que podem ser acarretados com esta produção científica. (Depoimento de aluno).

Portanto, além de termos o compromisso de investigarmos o que se pesquisa na área da educação nas duas realidades (Brasil e Angola) e de criar um laboratório local no Instituto, outro problema básico surgiu ao nos depararmos com a realidade angolana. Tínhamos, portanto, ao iniciar os trabalhos, demandas claras que envolviam a discussão da mudança do curso de Ensino de Psicologia para um curso de Psicologia Escolar; a discussão do perfil desse novo profissional; o levantamento dos problemas mais recorrentes no campo educacional em Angola que pudessem ser abordados com o referencial da Psicologia, Psicanálise e Educação; assim como efetivamente colaborar na construção de um laboratório e uma linha de pesquisas em nível de pós-graduação. A pesquisa, então, abarcou um universo maior do que havíamos previsto inicialmente.

Com base no que discutimos das duas universidades podemos afirmar que o cerne dos trabalhos do ISCED-UON até aquele momento estava centrado apenas no ensino, visando à produção acadêmica de estudos monográficos pelos licenciandos e na formação de mestres e doutores.

$\mathrm{Na}$ FaE-UFMG, além do ensino, a centralidade também está na pesquisa e na extensão. Isso, de saída, nos levou a perguntar: Qual é o papel da universidade pública em Angola em detrimento do papel da universidade pública no Brasil?

O ISCED-UON iniciou essa reflexão e demanda outro curso de graduação que visa, para além da formação de professores de Psicologia, a construir a formação de psicólogos do instituto em nível também da pós-graduação. Disso resultou a alteração da proposta inicial que passou a ressaltar a criação do Laboratório de Psicologia Psicanálise e Educação (LPPE-ISCED-UON), que vem servir de base fundamental para se operacionalizar a graduação e a pós-graduação da instituição africana no que tange ao seu campo de estudo.

Devemos ressaltar também que, contrastivamente, as concepções de Psicologia Educacional das duas universidades parceiras diferem muito e, para desenvolvimento do trabalho, optamos por conjugar, não sem tensão (como ve- 
remos a seguir), as duas concepções, denominando o profissional a ser formado no ISCED/UON em nível de graduação e pós-graduação de "Psicólogo Escolar e Educacional".

\section{Pesquisa Etnográfica Contrastiva e Interpretativa: Princípios Teórico-Metodológicos}

Já anunciamos que o trabalhado ocorreu numa perspectiva etnográfica, contrastiva e interpretativa (Geertz, 1989; Green, Dixon, \& Zaharlic, 2005; Gomes, Neves, \& Dominici, 2015), de acordo com três pressupostos: da Etnografia em Educação (Green \& cols., 2005), a concepção de sujeito/pessoa tanto da Psicologia Histórico-cultural de Vigotski (1934/1993; 1983/1995) quanto da Psicanálise de Freud (1923/2010a; 1933/2010b).

Do ponto de vista teórico-metodológico da Psicologia Histórico-cultural, compreendemos que a apropriação da realidade é uma construção dialética entre as pessoas que acontece nos níveis individual e social. Para Vigotski (1934/1993) a pessoa se individualiza ao apropriar-se do mundo que lhe é externo e constrói sentidos muito diversos para si mesma e para o mundo. Essa construção é sempre mediada pelo Outro, pela cultura e pela fala/linguagem. Mediação semiótica produzida nas e pelas interações sociais que é constitutiva das pessoas. Assim é no contexto da interlocução, vista como o processo de construção de significação (Pino, 1991) que as pessoas e suas práticas culturais são construídas.

Já o ponto de vista teórico-metodológico da Psicanálise sublinha essa ideia, reforça teorias que se pautam nas relações que o sujeito tem com a linguagem e acrescenta a elas a noção de inconsciente como efeito de tais relações. Cindido entre as normas reguladoras da cultura e as pulsões que visam à satisfação do desejo inconsciente, o sujeito sempre se ressente da angústia de não poder realizar plenamente esse desejo no âmbito social e moral. Freud (1933/2010b, p. 194) postula que "o Eu é o sujeito por excelência..., ele é divisível, e se divide durante várias de suas funções". Tais funções internalizam diferentemente as práticas culturais e morais do meio, e coabitam o sujeito ao mesmo tempo: parte de si tende a ser amoral, e subverter tais práticas; outra parte empenha-se em ser moral, e luta para se ajustar a elas; e outra, ainda, pode ser hipermoral, exigindo-Ihe tiranicamente sujeição a essas práticas ${ }^{3}$.

Segundo Gomes e cols. (2015), ao apropriar-se do mundo que o cerca o sujeito atribui sentido às suas práticas culturais e dependendo da cultura em que vive esses sentidos vão variar muito. Isso se estende, reconhece Pereira (2011), para os sentidos (hiper) morais que são internalizados no sujeito sob a forma inconsciente; sentidos esses que, depois de Freud, Pichon-Rivière (1983) irá fazê-los embasar sua metodologia psicanalítica de intervenção e de pesquisa no âmbito social - como veremos adiante.

3 "O Id é totalmente moral, o Eu se empenha em ser moral e o Supereu pode ser hipermoral." (Freud, 1923/2010a, p. 68).
Importa assinalar que a variação de sentidos das práticas culturais e dos valores morais internalizados pelos sujeitos/pessoas que estão nas duas universidades, foi analisada de modo contrastivo - e não comparativo. Pelo contraste podemos evidenciar as diferenças e semelhanças, sem necessariamente compará-las, entre o que esses sujeitos fazem acerca das práticas de ensino, de pesquisa e de extensão da FaE-UFMG e as práticas de ensino do ISCED-UON. Essa perspectiva contrastiva, que também é etnográfica e interpretativa, admite a necessidade de analisarmos as relações entre linguagem/discursos e culturas, conscientes e inconscientes, produzidas nas duas universidades considerando o neologismo languaculture (Agar, 1996; Green \& cols., 2005). Langua significa discurso, não apenas palavras e frases isoladas e culture são os sentidos/significados produzidos pelos participantes das culturas (Agar, 1996). Mais do que isto, é preciso compreender os pontos de vista dos sujeitos/ pessoas das diferentes culturas, de forma êmica (de dentro das comunidades) e ética (de fora das comunidades mantendo o respeito às diferenças culturais).

Reconhecemos que as atividades humanas são históricas, coletivas, pulsionais e dialéticas; mudam o tempo todo por meio das interações sociais e dos discursos (considerado como aquilo que se fala e o que se faz). Quais mudanças aconteceram nas práticas de ensino, pesquisa e extensão em ambas as universidades? A discussão da implantação do LPPE-ISCED-UON provocou alguma mudança nas práticas culturais dos professores do LAPED-FaE-UFMG e dos próprios professores do ISCED-UON que participam deste projeto? Para responder a essas perguntas pensamos ser importante refletir sobre o que aconteceu nos mais de dois anos de trabalho conjunto, ou seja, se faz necessário demonstrar nosso percurso de forma contrastiva e refletida.

\section{Missões de Trabalho e Estudos: construindo as bases de nossa parceria}

As Missões de Trabalho iniciais serviram ao propósito de firmar as bases teórico-metodológicas e os objetivos de nosso trabalho conjunto, quando foi descortinada também a problemática central do projeto: o quanto a formação de licenciados em psicologia no ISCED-UON não mais respondia ao que a sociedade cabindense necessita desse profissional. Seria necessário então, repensar o curso de graduação de Licenciatura em Psicologia do ISCED e construir o Curso de Pós-Graduação em Psicologia Escolar sob o ponto de vista da equipe angolana.

\section{Assentando as bases do trabalho e construindo uma linguagem comum}

Para realizar nosso trabalho conjunto organizamo-nos em grupos de trabalho com presença tanto de estudantes como de professores dos cursos de psicologia e de pedagogia do ISCED-UON. 
Embora já tivéssemos bastante informações sobre Angola, sua realidade político-social e suas demandas, por meio de leituras e de discussões junto aos professores angolanos, foi somente quando se chegou àquela cidade é que se começou a ter outra compreensão das discussões realizadas na FaE-UFMG. A perspectiva etnográfica contrastiva/ interpretativa (Geertz, 1989; Green \& cols., 2005; Gomes \& cols., 2015) nos forneceu uma ferramenta importante para compreendermos os sentidos atribuídos por nossos parceiros (professores e alunos da UON) que geravam novos significados, diferentes daqueles instituídos em nossa própria universidade (UFMG). Tomando por base o referencial de Vigotski (1934/1993) que entende a apropriação da realidade como uma construção dialética entre as pessoas, que acontece nos níveis individual e social, aquela realidade tão familiar (mesma língua, desigualdade econômica como marco das relações sociais, mesmo tipo de colonização) e tão diferente ao mesmo tempo, nos trouxe um estranhamento propício para a compreensão do que ali se passava. Esse estranhamento gerou Rich Points (Pontos Relevantes), que são

um conceito cunhado por Agar com o intuito de abranger os fatos que se tornam visíveis quando da diferenciação nos enquadres de referência. Pontos relevantes na etnografia são, pois, aqueles em que as diferenças de entendimento, ação, interpretação e participação se tornam marcadas. (Gomes, Fonseca, Dias, \& Vargas, 2008, p. 12).

Desde o início, pudemos observar as diferenças culturais/rich points expressas nas primeiras reuniões de trabalho como atestam nossas primeiras notas no Panorama Educação:

Algumas observações: as relações entre os professores no ISCED diferem daquelas instituídas na FaE, por sua formalidade. A começar pelos trajes: quase todos os homens usam terno e gravata. Pudemos observar a ausência das mulheres na reunião. A hierarquia foi citada várias vezes e não há quebra de protocolo. Todos debatem, mas a decisão é feita pelo professor com maior status na hierarquia. Existem diversos interesses que perpassam as falas e atitudes das diversas pessoas. O curso de Licenciatura em Psicologia está em pauta e corre o risco de ser extinto. É preciso dar um novo significado ao papel do psicólogo na comunidade angolana.(Notas de campo do Panorama Educação, 17/03/14).

Diante disso, propusemos uma dinâmica que priorizasse a escuta dos alunos e professores, por meio de Grupos Operativos. Duas questões iriam dinamizar as discussões dos grupos: "Quem é o profissional Psicólogo Escolar que a realidade de Angola exige hoje? Quais problemas esse profissional terá de enfrentar em sua prática?"

O que observamos como rich points de início foi o ineditismo da proposta de uma dinâmica participativa em que os estudantes podiam expressar livremente seus pontos de vista e suas concepções. Muitos deles comentaram que era a primeira vez em que se viam convidados a emitir sua opinião e relatar sua visão da situação desse profissional da educação. Neste sentido, os aspectos mais relevantes na visão dos estudantes foram: a falta de uma identidade profissional de quem se forma como Licenciando em Psicologia; o desvio de sua função ao iniciar seus trabalhos na escola; a complexidade da realidade nas escolas angolanas que exige um trabalho qualificado; a precarização do profissional formado no curso de Licenciatura em Psicologia.

Em relação ao primeiro aspecto, a identidade profissional, percebemos uma sobreposição dos campos da Educação, Psicologia, Psicanálise com a inclusão de um campo pouco definido denominado Psicopedagogia. Em decorrência dessa sobreposição, o próprio ofício do psicólogo e, em especial, do psicólogo escolar foi problematizado denotando uma necessidade de maior esclarecimento conceitual desses diversos campos. Essa afirmativa pode ser melhor evidenciada nas falas dos participantes:

"A falta do devido enquadramento do Pedagogo e Psicólogo no local de trabalho motivado pelo fato das suas formações serem muito generalizadas (gerais)"

O que necessitamos: um psicopedagogo que saiba ouvir, compreender os fenômenos educativos; um psicólogo que tenha a componente psicanalítica social; um psicólogo que possa compreender as crianças; o status de psicopedagogo em nossa sociedade; um psicopedagogo que saiba compreender o mal-estar nas escolas (Síntese dos grupos de trabalho em 20/03/14).

O segundo aspecto, o desvio da função do Licenciado em Psicologia, foi muito recorrente na fala dos participantes. Esses profissionais se formam e acabam por executar a função de um professor de qualquer área de conhecimento, uma vez que não há postos suficientes para a ocupação dos professores de Psicologia no mercado de trabalho e há falta de professores de outras áreas.

Na minha opinião, estes profissionais terão de enfrentar certos problemas em suas práticas visto que um professor formado em Psicologia ou ensino de Pedagogia metem a lecionar a disciplina de Matemática ou até mesmo a Química. Este mesmo docente terá certos problemas na transmissão de conteúdos.(Síntese dos grupos de trabalho em 20/03/14)

O terceiro aspecto traz à tona traços das dificuldades vivenciadas por esse profissional quanto à realidade social e econômica da população atendida nas escolas em Cabinda:

O deficiente relacionamento entre a escola e família e vice-versa, as dificuldades sociais dos alunos, entre eles, a falta de acompanhamento da formação dos filhos por parte dos pais, a falta de normas, condições econômicas e ou financeiras para transporte, alimentação, a compra de materiais didáticos... Alunos crianças com problemas psicológicos tais como: frustração, abandono dos pais ou 
um dos progenitores [famílias monoparentais]... O excessivo número de alunos nas turmas (60, até 90 crianças ou adolescentes) ao contrário dos 35 recomendados. (Síntese dos grupos de trabalho em 20/03/14)

O último aspecto apresenta as dificuldades relativas à pauperização da profissão do professor e de suas condições de trabalho:

$\mathrm{Na}$ escola hoje os professores estão desmotivados em função dos salários auferidos e das condições de trabalho. Professores com problemas de alcoolismo. Indisciplina nas salas de aulas, vandalização da estrutura escolar. Falta de condições no local de serviço (salas de aulas em más condições, sem carteiras, falta de casas de banho, crianças tendo aula ao ar livre). (Síntese dos grupos de trabalho em 20/03/14)

Esses quatro aspectos da realidade educacional de Cabinda vêm corroborar os estudos monográficos realizados por estudantes dos diversos cursos do ISCED. Segundo Canhici \& Gomes (2016, p. 22), ficaram em evidência,

O funcionamento e condições de trabalho das escolas:

a) Insuficiência de material didático, bibliotecas e laboratórios;

b) Inadequação de metodologias usadas no ensino das diversas disciplinas;

c) Falta de formação dos professores em áreas específicas;

d) A não capacitação sistemática do corpo docente;

e) Superlotação das salas de aula, como fruto da reforma obrigatória.

Para além desses fatores, que foram apontados pelos autores das monografias como causas das dificuldades escolares, as diferenças linguísticas entre a língua que se fala nas escolas (Português) e nas casas das crianças (Ibinda) foram também consideradas como fator importante dessas dificuldades.

Nota-se que os estudantes não trazem à tona apenas a formação de um Psicólogo Escolar com função adaptativa, que atenda às necessidades do mercado de trabalho, de empregabilidade dos finalistas e de melhoria da qualidade do ensino e aprendizagem nas escolas de Cabinda, mas de um "psicólogo/psicopedagogo" que atenda às necessidades das pessoas que estão nas escolas, que compreenda o mal-estar em que vivem, aliando essas necessidades à compreensão dos fenômenos educativos e suas dificuldades estruturais e conjunturais. Parece que os estudantes apresentam a necessidade de perceber criticamente o funcionamento das escolas, a tensão entre a língua que se valoriza dentro e fora de- las, indicando a necessidade de se formar o psicólogo escolar para além do olhar individualizado e adaptativo dos sujeitos que participam da comunidade escolar Cabindense. Essa perspectiva de formação do Psicólogo Escolar está mais próxima da perspectiva da equipe brasileira que participa dessa parceria ISCED-UON e FaE-UFMG.

Tal perspectiva nos leva a usar os termos Psicologia da Educação ou Psicologia Educacional e não mais Psicologia Escolar, como tende a ser adotado pela UON. O termo Psicologia da Educação representa uma mudança de concepção do que vem a ser a formação dos psicólogos que atuam em escolas, isto é, representa segundo Gomes,

o deslocamento progressivo da concepção de psicologia aplicada à educação para a concepção da psicologia da educação como uma disciplina-ponte, segundo Salvador, provoca a substituição progressiva de um tipo de intervenção clínica ou médica, centrada, sobretudo, no diagnóstico e no tratamento dos transtornos do desenvolvimento e da conduta (Psicologia Escolar), para uma intervenção mais específica, do tipo educativo, centrada nos problemas e nas dificuldades de aprendizagem dos alunos e no trabalho escolar. (Gomes, 2010, pp. 8-9)

Nossa parceria pretende que mesmo com o uso do termo Psicologia Escolar nossos parceiros da UON avancem para uma prática de formação que procure

analisar o ser humano em sua singularidade, porém, sem perder de vista o que nele há de comum com outros seres humanos e o fato de ele ser historicamente determinado e construtor de sua história. Dentro do corpo de conhecimento da psicologia e da psicologia da educação, construíram-se bases teóricas que levassem em conta, também, a estrutura social mais ampla, contribuindo, assim, para a compreensão de fenômenos complexos como o autoritarismo, a opressão, as lutas pelo poder. (Goulart, 1989 citado por Gomes, 2010, p. 9).

Essa postura, segundo Gomes (2010), tem como pressuposto básico que o objeto de estudo da Psicologia, em geral, e da Psicologia da Educação é o ser humano em contextos educativos visto como ser histórico e social que constrói sua subjetividade nas relações com outros seres humanos. Isso, portanto, exige de nós, formadores de alunos/professores da Educação Infantil ao Ensino Superior, constantes reformulações de nossas práticas educativas e diálogo com outras áreas do conhecimento.

Dessa forma, concordamos com Sadalla e cols. (2005, p.241, citado por Gomes, 2010, p. 16):

Precisamos lançar um novo olhar para a disciplina Psicologia da Educação, concebendo-a como uma disciplina que, dotada de conhecimentos próprios, considere tanto os fatores psicológicos, quanto a realidade dos processos educativos, admitindo-os numa inter-relação, ao invés de uma aplicação de teorias à prática educativa. 
Outro tema fundamental diz respeito ao tempo. Com o decorrer do trabalho em conjunto, outros pontos contrastivos tornaram-se mais evidentes e perpassam a visão de psicólogo que se forma no ISCED-UON. Afora as relações estabelecidas na própria universidade e o perfil do psicólogo escolar, a relação com o tempo nos chamou muito a atenção. Os estudantes frequentam as aulas e vão embora, não têm tempo de estudos no Instituto, fora da sala de aula. Por exemplo, bolsas de Iniciação Científica, de pesquisa ou de extensão são inexistentes na UON como um todo. A maioria dos alunos já tem família a sustentar e precisa trabalhar no outro horário do dia. Isto contrasta com a realidade das universidades públicas brasileiras que preveem esse tempo de estudos fora da sala de aula destinando bolsas de várias modalidades aos estudantes com o objetivo de se formar professores pesquisadores nas diversas áreas do conhecimento.

O tempo tem sido uma categoria pouco explorada nos estudos sobre a educação, tanto em relação à sua racionalização (expressa nas formas de organização) como suas cadências e ritmos que se entrecruzam no cotidiano dos docentes e discentes, constituindo a vida desses sujeitos (Teixeira, 1999). Pouco problematizado e tomado, muitas vezes, como acessório, como mero elo organizador das distintas práticas (Bondioli, 2004), o tempo vivenciado por nós em Cabinda mostrou-se como um amálgama que rompia as barreiras do público e do privado, da vida profissional e pessoal, trazendo uma dimensão ainda não pensada por nós.

Os tempos, aqui no Brasil, regidos por dois turnos bastante rígidos, foram vivenciados na UON de forma distinta, sem que houvesse tanta preocupação com a pontualidade. Podemos dizer que o respeito à hierarquia é uma prática cultural muito importante naquela comunidade; não se inicia um evento sem as presenças de professores que ocupem cargos superiores como Reitor, Vice-reitor ou Decanos (Diretores de Faculdades, no Brasil). E, se por algum motivo há atrasos por parte desses professores, a espera é algo que faz parte da rotina dos eventos daquela comunidade educativa. Mesmo as reuniões de trabalho na universidade não eram regidas pelo tempo que usualmente costumávamos atender. Esses fatos, recorrentes, nos dão indícios de que, da perspectiva angolana, aqueles acontecimentos não eram lidos como atrasos, como aconteceria na perspectiva brasileira, mas como outra forma de produção e apropriação do tempo por nossos parceiros. Essa forma de vivenciar e gerenciar o tempo constituiu-se como uma categoria contrastiva importante que trazia um diferencial nos momentos de planejamento das atividades que iriam se realizar no LPPE, ainda embrionário.

Outra característica a ser destacada nessa dimensão temporal, além de sua forma peculiar de ser vivenciada por nossos colegas angolanos, é seu hibridismo. Diversas temporalidades se amalgamam formando uma tessitura sui generis. Tempos de trabalho, tempos de família, tempos de passeio ou tempos de ir às compras não possuíam contornos muito bem delineados, pelo menos da forma como nós, professores da universidade brasileira estávamos acostumados a vivenciar. O tempo de casa/trabalho, já tão mesclado em nossa realidade atual, no ISCED/UON possuía componentes novos que rompiam com apropriações que já tínhamos incorporado sobre essas diversas temporalidades. Assim, em Cabinda, era comum estarmos em um "horário de trabalho" (como no meio de uma tarde em um dia de semana) e recebermos alguma visita social de colegas da UON. Isso exigiu-nos repensar nossa lógica cartesiana que dicotomiza trabalho e cuidado com as pessoas. Assim, tivemos de incluir outras dimensões das relações sociais que constituem as pessoas em uma sociedade e entender o cuidado que nossos parceiros tinham por nós, pois sempre perguntavam se estávamos bem atendidos, se precisávamos de algo, tanto necessidades relativas à nossa sobrevivência, quanto àquelas relativas ao nosso trabalho.

Essas sobreposições de significados sociais e sentidos pessoais (Vigotski, 1934/1993) tornavam, do nosso ponto de vista, a dimensão temporal híbrida, amalgamada. Dimensão cuja natureza de trabalho não exigiu cronogramas precisos, alternando momentos de atividade intensa e de ociosidade, um tempo amalgamado entre o tempo das tarefas e o tempo do relógio; em que muitas vezes prevaleceu o tempo das tarefas, que de acordo com Thompson (1998, pp. 271-272) faz "pouca separação entre o 'trabalho' e a 'vida'... as relações sociais e o trabalho são misturados - o dia de trabalho se prolonga ou se contrai segundo a tarefa - não há grande senso de conflito entre o trabalho e "passar o dia". $E$, dessa forma, "aos homens acostumados com o trabalho marcado pelo relógio, essa atitude para com o trabalho parece perdulária e carente de urgência" (Thompson, 1998, pp. 271-272).

Dimensionar a realização das tarefas tendo por base um tempo híbrido com características pouco definidas tornou-se um grande desafio. Pudemos, nessa vivência, aprender a apreciar o tempo de outra perspectiva, talvez menos tensa, focalizada no momento presente.

Outro aspecto importante a ser retomado e destacado foi a possibilidade de termos uma escuta dos alunos e professores em uma plenária final de síntese das questões propostas sobre qual psicólogo se quer formar no ISCED-UON. Não pensávamos que essa dinâmica iria provocar tanto estranhamento, ou seja, não parecia ser comum agregar a voz dos estudantes em um evento como um seminário ou congresso. Uma evidência desse fato encontra-se na fala do coordenador, do lado angolano, quando disse que era a primeira vez que um país (no caso, o Brasil) realizava um trabalho conjunto com Angola. As relações anteriores baseavam-se ou na exploração de suas riquezas materiais ou em uma relação autoritária que ditava aos angolanos o que deveria ser feito. Dessa forma, ficou bastante evidente um novo contrato de relação onde ambos os parceiros se respeitavam e aprendiam uns com os outros.

Essa primeira missão de estudos colocou as bases sobre as quais o trabalho se desenvolveu permitindo a concretização de nossos objetivos, ou seja, a destinação de um espaço físico para o Laboratório de Psicologia, Psicanálise e Educação (LPPE) e o início de um trabalho mais efetivo 
das duas equipes: a brasileira e a angolana no sentido de se construir o perfil do psicólogo que se quer formar no ISCED/ UON.

\section{O funcionamento do LPPE e a formação de psicólogos no ISCED-UON}

De posse dos dados, das temáticas e produções dos alunos do ISCED-UON e do extenso trabalho diagnóstico desenvolvido na sede daquele instituto, passamos coletivamente a conceber a materialidade e a implantação do LPPE. Consideramos o laboratório como lócus orgânico de todas as ações e iniciativas acadêmicas de Psicologia, Psicanálise e Educação endereçadas e inscritas nele. Mais do que um mero espaço físico, o LPPE deverá fundamentar a Linha de Pesquisa, reunir toda a produção na área e criar um sítio para onde se deve convergir o ensino, a pesquisa e a extensão realizados pelo instituto. Para além da pesquisa, como inicialmente projetamos, percebemos a necessidade de fomentar os três pilares fundamentais que sustentam as atividades de uma universidade contemporânea, agora, a serem estendidos também à UON. Com a implantação do LPPE, e conhecendo melhor a realidade local, redimensionamos seus objetivos que passaram a ser os seguintes: (a) Contribuir para a delimitação e efetivação de uma Psicologia propriamente angolana e africana; (b) Vetorizar as atividades do campo psi da UON aplicadas à educação; (c) Consubstanciar a formação em nível de graduação e de pós-graduação do ISCED; (d) Auxiliar no aprimoramento de métodos de ensino dos professores atuais do Instituto; (e) Ampliar o espaço de trabalho do licenciado em Psicologia (Psicólogo Escolar e Educacional) na província de Cabinda; (f) Instituir uma revista indexada e congressos bienais em nível internacional; (g) Promover intercâmbios de discentes e de docentes do ISCED; e (h) Contrastar estudos de Angola com os de outros países em Psicologia, Psicanálise e Educação.

Para alcançar tais objetivos, decidimos propor um organograma de funcionamento do LPPE-ISCED-UON, baseado metodologicamente no Grupo Operativo, proposta como técnica de pesquisa-intervenção pelo psicanalista argentino Pichon-Rivière (1983). O Grupo Operativo permite transformar uma situação coletiva em um campo de investigação e, ao mesmo tempo, de ação, de maneira não necessariamente diretiva, cujos sujeitos participantes com suas divisões e concepções (hiper)morais, e sem serem necessariamente especialistas, tornam-se ativos protagonistas tanto na produção de conhecimento como nos sentidos das práticas que dão significado à sua experiência vivida. Essa técnica pauta-se numa dimensão social da Psicanálise e nas possibilidades concretas de aprendizagem contínua e de protagonismo do sujeito e do grupo de produzir seu próprio referencial conceitual que seja operativo da realidade e de seu aprendizado.

Durante uma greve de enfermeiros de um hospital argentino em que atuava, Pichon-Rivière (1983) convocou os pacientes menos graves para assistir aos mais comprome- tidos e notou que todos, os mais e os menos graves, apresentaram franca melhora em sua condição clínica, mesmo não sendo conhecedores técnicos dos cuidados de saúde. Ele passou, então, a estudar o fenômeno e a fundamentar os pressupostos teórico-metodológicos do que chamou Grupo Operativo. A partir do vínculo entre os integrantes e a tarefa como norteadora é possível que um grupo examine o fenômeno, teorize-o de maneira própria, reconheça os obstáculos, socialize as possibilidades de ação, geste alternativas para superar as dificuldades, aprenda e comungue os resultados.

No caso do LPPE-UON, percebemos que seus componentes, alunos e professores, tinham pouco ou quase nenhum conhecimento e inserção em atividades mais elaboradas de publicação, de extensão, de pesquisa e mesmo de ensino. Assim como se deu com os pacientes de Pichon-Rivière, julgamos necessário criar vínculos e tarefas que unissem o corpo acadêmico no sentido de construir as bases fundantes do laboratório em que os sujeitos mais experientes ou conhecedores, ainda que não plenamente, auxiliam os outros com menos inserção. Para alcance dos novos objetivos, criamos então os Grupos Operativos como subdivisão do LPPE, com vínculo e tarefa específicos, sem desconhecer os limites de cada um e das concepções morais dos sujeitos que os compuseram. Foram eles: Grupo de Trabalhos (GT); Grupo de Publicação (GPU); Grupo de Ensino (GEN); Grupo de Pesquisa (GPE); e Grupo de Extensão (GEX).

Nota-se que, com essa iniciativa de implantação do laboratório, estamos possibilitando uma verdadeira convulsão interna no sentido de ampliarmos conjuntamente a visão e o funcionamento seguindo os parâmetros de uma instituição acadêmica internacional. É notável o quanto a atuação universitária da UON se reduz quase que exclusivamente ao ensino e à formação do Licenciado em Psicologia, mas pensamos que se fez nascer com os Grupos Operativos do LPPE a necessidade de também atuar na extensão e na pesquisa, de ampliar o diálogo com a Psicanálise, associada ao campo educativo, de promover intercâmbios entre discentes e docentes, bem como de possibilitar a promoção da internacionalização da UON como um todo. Mais do que isto: proporcionou-se a reflexão sobre qual psicólogo se quer formar no ISCED-UON em níveis de graduação e pós-graduação, para além das perspectivas clínica e pragmática que inicialmente delinearam-se nas primeiras discussões entre as duas equipes.

\section{Conclusão}

Em conclusão, criamos e implantamos um laboratório que une diferentes profissionais de educação do ISCED-UON, o LPPE, procurando construir unidade de ação na diversidade por meio dos Grupos Operativos. Isso difere de nosso laboratório na FaE-UFMG, o LAPED, que congrega diferentes núcleos e grupos de pesquisa, mas cada um funcionando independentemente. Não há uma 
organização que pouco congregue ações conjuntas de seus pesquisadores. De acordo com a perspectiva contrastiva, podemos dizer que o LPPE, de Cabinda, passou a ser organicamente melhor instituído do que o LAPED, em Belo Horizonte. Evidentemente, desde sua instituição em 1998, o laboratório brasileiro já possui uma substancial trajetória, reunindo profissionais de referência nacional com seus orientandos e bolsistas. Todavia ele tende a funcionar menos orgânico e mais individualmente, dadas as condições políticas e de financiamento de pesquisas que hoje temos no Brasil, que fomentam iniciativas individuais de investigação. Os subgrupos e núcleos do LAPED atuam praticamente como células autônomas, às vezes, em torno de apenas um professor-referência e de seus alunos. Já o laboratório angolano, inaugurado em 2015 e não tendo, por isso, trajetória ainda suficiente para dizer como as experiências acadêmicas ocorrerão, foi pensado idealmente de acordo com a realidade local. Baseamo-nos em Grupos Operativos que esvaziam um pouco o lugar de individual de referência e estimulam o trabalho coletivo e a participação ativa de sujeitos de maneira menos diretiva. Trata-se de considerar tais sujeitos numa perspectiva psicossocial das práticas culturais e dos valores morais da experiência real que é bastante cara aos proponentes brasileiros e angolanos que instituíram o LPPE. Isso pressupõe muitas vozes e discursos presentes, mesmo que ausentes do diálogo. Do ponto de vista Bakhtinano, recuperado por Gomes, (2015),

as palavras não são transparentes, mas polifônicas, polissêmicas e opacas. Porque não são neutras, elas constroem relações de poder e significações para os modos de viver, sentir, pensar e dizer das pessoas de determinada sociedade. Esses modos variam de geração para geração, de sociedade para sociedade, de grupos culturais para grupos culturais, são dinâmicos, e, portanto, sociais e históricos, não há como perpetuá-los sem que ocorram mudanças de significações ao longo do tempo. Os rituais (casamento, nascimento, etc.) podem se perpetuar, mas as diferentes gerações constroem significações diversas para os mesmos. (Gomes, 2015, p. 4) .

Desse modo, pensamos que as práticas culturais do ISCED-UON, aqui analisadas, relativas ao tempo de trabaIho, papel e função das universidades, formação de psicólogos, relações entre professores e alunos vem sofrendo transformações e com a criação do LPPE criam-se também novas possibilidades de modificar outras práticas culturais, produzir outros discursos e alterar princípios, conteúdos e formas de efetivação de trabalhos acadêmicos tanto em Cabinda quanto em Belo Horizonte, no que concerne ao campo da Psicologia Escolar e Educacional numa parceria comum.

Esse trabalho nos levou igualmente ao diálogo, nos tirando de nossos trabalhos individualizados, pois os membros da equipe brasileira se viram em contextos de aos outros, numa perspectiva operativa.

\footnotetext{
4 Texto escrito para inauguração do LPPE-ISCED-UON, ainda não publicado.
}

Professores e alunos participantes reavaliaram muitas certezas e práticas próprias, reelaboraram suas maneiras de socialização, de trato com o outro, com menos resistências e imposições. Permitiu-nos também repensar o funcionamento do LAPED e apurar o nosso olhar para nossas diferenças culturais, psicossociais e acadêmicas.

\section{Referências}

Agar, M. (1996). Language shock: understading the culture of conversation. New York: Harper Collins.

Bembe, M. D. (2013). A questão de Cabinda uma visão estratégica: evolução da situação e cenários de futuro. Lisboa: Edição de Angola.

Bondioli, A. (Org.). (2004). O tempo no cotidiano infantil: perspectivas de pesquisa e estudos de caso. São Paulo: Cortez. (Trabalho original publicado em 2002).

Canhici, M.H. (2014). Estudo sistemático de monografias dos finalistas do ISCED/UON sobre Dificuldades de Aprendizagem (2006-2011). Dissertação de Mestrado, Universidade Federal de Minas Gerais, Belo Horizonte, Minas Gerais.

Canhici, M. H.; Gomes, M. F. C. (2016). Dificuldades escolares em Cabinda/Angola: o que dizem as monografias? Psicologia em Estudo, 21(3), 485-496.

Centro de Documentação e Pesquisa Helena Antipoff [CDPHA] Faculdade de Educação, Universidade Federal de Minas Gerais. Recuperado: 30 jun. 2015.Disponível: https://cdpha.wordpress. $\mathrm{com} /$

Decreto lei n. 07/09 (2009, 12 de maio). Reorganização das Redes de instituições de Ensino Superior Públicas. Angola: Diário da República.

Freud, S. (2010a). O Eu e o ld. Em Obras Completas (vol. 16.). São Paulo: Companhia das Letras. (Trabalho original publicado em 1923).

Freud, S. (2010b). Conferência 31: Dissecação da personalidade psíquica. In: Obras Completas (vol. 18). São Paulo: Companhia das Letras. (Trabalho original publicado em 1933).

Geertz, C. (1989) A interpretação das culturas. Rio de Janeiro: LTC,

Gomes, M. F. C. (2010). Psicologia da Educação e Formação de Professores (1a. ed.). Belo Horizonte: Faculdade de Educação/ UFMG.

Gomes, M. F. C. (2015). Laboratório de Psicologia, Psicanálise e Educação: um diálogo entre culturas. Texto apresentado no evento de inauguração do LPPE/ISCED/UON. (Texto não publicado). 
Gomes, M. F. C.; Fonseca, M. C. F. R; Dias, M. T. M.; Vargas, P. G. (2011). Culture, Cognition and Language in the Constitution of Reading and Writing Practices in an Adult Literacy Classroom. Psicologia: reflexão e crítica,24(3), 561-569.

Green, J. L.; Dixon, C. N.; Zaharlic. A. (2005). A etnografia como lógica de investigação Educação em Revista, 42, 13-79.

Instituto Superior de Ciências da Educação [ISCED] (2014). Conceito de Psicologia Escolar (generalidades), Universidade 11 de Novembro, Cabinda. Texto em construção.

Pereira, M. R. (2011). Acabou a autoridade? Professor, subjetividade e sintoma. Belo Horizonte: Fino Traço/FAPEMIG.

Pino, A. (1991). O conceito de mediação semiótica em Vigotski e seu papel na explicação do psiquismo humano. Cadernos CEDES, 24, 38-51.
Pichon-Rivière, E. (1983). O processo grupal. São Paulo: Martins Fontes.

Teixeira, I.A.C. (1999). Cadências escolares, ritmos docentes. Educação e Pesquisa, 25(2), 87-108.

Thompson, E. P. (1998). Costumes em comum: estudos sobre a cultura popular tradicional. São Paulo: Companhia das Letras.

Vigotski, L. S. (1993). Obras Escogidas (vol. II.). Madrid: Aprendizaje Visor. (Trabalho original publicado em 1934).

Vigotski, L. S. (1995). Obras Escogidas (vol. III.). Madrid: Aprendizaje Visor. (Trabalho original publicado em 1983).

Recebido: 20 de julho de 2017 Aceito: 09 de maio de 2018 unrestricted use, distribution and reproduction in any medium, provided the original article is properly cited. 